\title{
Reproductive History
}

National Cancer Institute

\section{Source}

National Cancer Institute. Reproductive History. NCI Thesaurus. Code C17655.

An account of all reproductive events and problems a person has experienced. An important aggregate factor in epidemiological studies of women's health. The concept usually includes the number and timing of pregnancies and their outcomes, the incidence of breast feeding, and may include age of menarche and menopause, regularity of menstruation, fertility, gynecological or obstetric problems, or contraceptive usage. 